\title{
Capsule Commentary on Schifferdecker et al., Knowledge and Perception of Breast Density, Screening Mammography, and Supplemental Screening: in Search of "Informed"
}

\author{
H. Douglas Walden, MD, MPH \\ Saint Louis University, St. Louis, MO, USA. \\ J Gen Intern Med 35(6): 1934 \\ DOI: $10.1007 / \mathrm{s} 11606-020-05793-3$ \\ (c) Society of General Internal Medicine 2020
}

$\mathrm{S}$ chifferdecker et al. ${ }^{1}$ conducted a qualitative analysis of 443 focus group excerpts from 47 women with a normal mammogram and dense breasts to explore the women's reasons for undergoing breast cancer screening, their knowledge of breast cancer risk factors, the information they received about and knowledge of breast density, and experiences and questions about supplemental imaging. About half of all women knew that they had dense breasts, but most had limited knowledge of what this meant. Most of the women desired more information on breast density and its implications for screening. Investigators concluded that insufficient understanding of risks, benefits, and potential harms of supplemental screening exists.

Breast cancer screening is complicated for both clinicians and their patients. A variety of organizations have developed screening guidelines that differ in specifics and often fail to discuss supplemental screening strategies. ${ }^{2}$ Clinicians may overestimate their patients' understanding of their own health risks. Even well-educated individuals can face health literacy issues when they are not familiar with medical terminology or with the benefits and risks of various diagnostic tests. In 2008, Cavanaugh et al. ${ }^{3}$ provided a striking example. More than half of diabetic outpatients could not understand titration instructions for long-acting insulin, and a quarter could not identify which blood glucose values were within their target range. Poor numeracy skills were associated with worse perceived self-efficacy and fewer self-management behaviors. Results of this qualitative study of breast cancer screening suggest that the same could apply to breast cancer screening and breast density.

Published online March 24, 2020

\section{REFERENCES}

1. Schifferdecker KE, Tosteson AA, Kaplan C, Kerlikowske K, Buist DSM, Henderson LM, Johnson D, Jaworski J, Jackson-Nefertiti G, Ehlerich K, Marsh MW, Vu L, Onega T, Wernli KJ. Knowledge and perception of breast density, screening mammography, and supplemental screening: In search of "informed." J Gen Intern Med. https://doi.org/10.1007/s11606019-05560-z

2. https://www.cdc.gov/cancer/health-care-providers/resources.htm. Accessed 12/2/2019

3. Cavanaugh K. Huizinga MM, Wallston KA, Gebretsadik T, Shintani A Davis D,, Gregory RP, Fuchs L, Malone R, Cherrington A, Pignone M, DeWalt DA, Elasy TA, Rothman RL. Association of Numeracy and Diabetes Control. Ann Intern Med 2008; 148:737-746

4. Engmann NJ, Golmakani MK, Miglioretti DL, Sprague BL, Kerlikowske K. Population- Attributable Risk Proportion of Clinical Risk Factors for Breast Cancer. JAMA Oncol. 2017;3(9):1228-1237

Publisher's Note: Springer Nature remains neutral with regard to jurisdictional claims in published maps and institutional affiliations. 